\title{
STRESS IN AN ELASTIC BEDROGK HUMP DUE TO GLACIER FLOW
}

\author{
By L. W. MORLAND \\ (School of Mathematics and Physics, University of East Anglia, University Plain, Norwich \\ $\mathrm{NR}_{4} 7 \mathrm{TJ}$, England) \\ and E. M. MORRIs* \\ (School of Environmental Sciences, University of East Anglia, University Plain, Norwich \\ NR4 7 TJ, England)
}

\begin{abstract}
The stress field in an isotropic elastic hump representing a typical bedrock feature is obtained for plane strain conditions. Gravity effects are included and the applied load is a normal pressure distribution deduced from an idealized model of glacier flow. A Coulomb failure criterion is applied, including the effective stress change due to pore-water pressure, and stresses on the predicted failure planes determined for different pressure amplitudes and relative gravity contributions. The latter make little difference to the maximum "failure stress" but influence the regions where such stress levels occur. Levels of cohesive stress required to inhibit Coulomb failure are obtained, and are low in general, implying that coherent rock in the adopted hump profile, subject to the model pressure, would not fail. That is, this profile is stable unless jointing introduces an easier failure mechanism.
\end{abstract}

RÉsumé. Efforts dus à l'écoulement d'un glacier dans une protubérance élastique du lit rocheux. Le champ des contraintes dans une protubérance isotrope représentant une caractéristique typique du lit rocheux est obtenu pour des conditions de déformation dans un plan. Les effets de la gravité sont pris en compte et la charge appliquée est une distribution normale des pressions déduites d'un modèle idéal d'écoulement glaciaire. On applique un seuil de rupture de Coulomb, en tenant compte des changements réels introduits dans les contraintes par la pression capillaire de l'eau et des efforts sur les plans de rupture probables déterminés pour différents niveaux de pression et de contribution relative de la gravité. Cette dernière change peu de la valeur de la "charge de rupture" maximum mais modifie les régions où de tels niveaux de contrainte se produisent. L'intensité des forces de cohésion nécessaires pour empêcher la rupture de Coulomb est calculée et se trouve faible en général, ce qui implique qu'un rocher cohérent dans le profil adapté pour la protubérance, soumis aux pressions du modèle, ne rompra pas. C'est-à-dire que ce profil est stable, à moins qu'une diaclase n'introduise un mécanisme de rupture plus facile.

Zusammenfassung. Spannung in einem elastischen Buckel am Felsuntergrund infolge des Gletscherflusses. Der Spannungszustand in einem isotropen, elastischen Buckel als einer typischen Erscheinung am Felsuntergrund lässt sich als ebenes Spannungsfeld beschreiben. Schwerkraftwirkungen werden berücksichtigt; die aufgebrachte Last ist eine Normaldruckverteilung, hergeleitet aus einem idealisierten Modell des Gletscherfliessens. Ein Coulomb-Bruchkriterium wird eingeführt, das die wirksame Spannungsänderung infolge des Druckes im Porenwasser berücksichtigt; die Spannungen an den vorberechneten Bruchebenen werden für verschiedene Druckamplituden und relative Schwerkraftanteile bestimmt. Die letzteren verändern die maximale "Bruchspannung" nur wenig, beeinflussen aber die Bereiche, wo solche Spannungsflächen auftreten. Es ergeben sich Flächen kohäsiver Spannung, die zur Verhunderung des Coulomb-Bruches notwendig sind; sie liegen im allgemeinen tief, woraus zu folgern ist, dass kohärenter Fels in dem angenommenen Buckelprofil, dem das Druckmodell gilt, nicht nachgeben wird. Dies bedeutet, dass das Profil stabil ist, es sei denn, Gelenkbildung würde einen leichteren Bruchmechanismus bewirken.

\section{INTRODUCTION}

A recent paper by Morland and Boulton (1975) presents an analytic solution and computer calculation of the stress in an isotropic elastic hump in plane strain under applied surface loads. The effects of glacier flow are modelled by assuming an idealized normal pressure distribution deduced from Nye's ( 1969 ) wavy-bed sliding theory, ignoring the restriction to small slopes. On this basis the distribution of local maximum shear stress is determined in order to predict likely failure zones, and the global maximum shear stress is obtained to compare with a failure stress of any given material. The stress field is independent of the elastic moduli of the rock. This analysis is now complemented by including the effects of gravity on the stress field, and by making a more detailed examination of the stress field in

* Now at Institute of Hydrology, Wallingford, Oxfordshire OXı 8BB, England. 
relation to a Coulomb failure criterion. The body-force contribution was included in an analysis of flute formation on a horizontal bed by Morris and Morland (1976), and for completeness we now incorporate an inclination of the mean bed line to the horizontal.

The Coulomb criterion is expressed as an inequality between a dimensionless failure stress $S$, which depends on the local stress and the friction angle $\phi$, and a critical value $S_{\mathrm{c}}$ which depends only on the cohesive stress $\tau_{0}$, angle $\phi$, pore-water pressure $p_{\mathrm{w}}$ and the chosen stress unit. Failure occurs when $S$ exceeds $S_{\mathrm{c}}$. It is found that gravity influences the location of zones where $S$ approaches its maximum value, and hence the likely regions of failure. However the gravity contribution has no significant effect on the maximum value of $S$ attained, at least for the chosen hump profile and model pressure distribution, so will not seriously influence the predictions of failure. Essentially, the amplitude of the model pressure distribution far exceeds the variation of body-force stress through the depth of the hump, and the gravity terms are dominated by applied surface pressures.

Since the presence of pore-water pressure reduces the effective stress in the Coulomb criterion, the effect of pore pressure up to the ice overburden pressure is considered. However, it is found that for the adopted hump profile and model pressure distribution, Coulomb failure is unlikely in coherent rock except for glaciers with very high basal sliding velocities, implying a stable hump profile under the adopted conditions. A more skew hump, and corresponding pressure distribution, may lead to higher failure stress, or a jointed rock system to different and easier modes of failure. However, a more realistic determination of the applied pressure distribution, and possible tangential traction due to glacier flow over a hump with finite slope, is required before reliable predictions can be claimed.

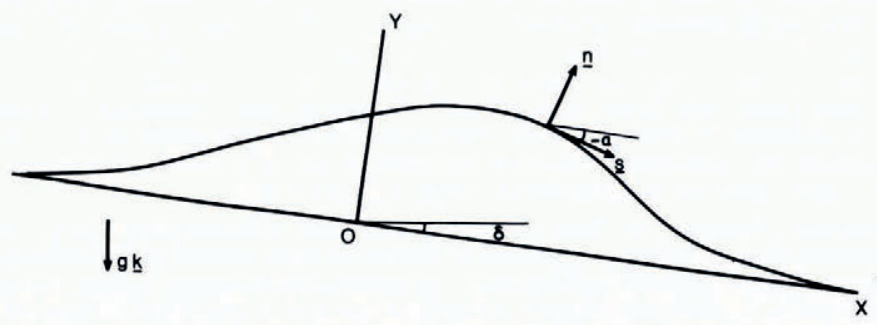

Fig. I. A moderately skew hump on a mean bed line inclined at angle $\delta$ to the horizontal. $\mathbf{n}$ and $\mathbf{s}$ are unit vectors normal and tangential to the hump contour respectively. $\alpha$ is the local inclination of $\mathbf{s}$ to $O X$. The gravity force per unit mass, $g \mathbf{k}$, acts vertically downwards.

\section{Stress field in the elastic humP}

Consider a single plane hump on a mean bed line $\mathrm{O} x$ inclined at angle $\delta$ to the horizontal (Fig. I). The bed surface approaches $\mathrm{O} x$ as $x \rightarrow \pm \infty$. Introduce dimensionless coordinates $\mathbf{x}=(X, r)$ by

$$
x=a X, \quad y=a r
$$

so that the hump amplitude is approximately unity in $(X, Y)$ coordinates. The moderately skew hump shown in Figure $\mathrm{I}$ has a boundary defined by $\operatorname{Im}(\zeta)=0$ in the conformal mapping

$$
z=\zeta+\frac{0.5}{\zeta-\mathrm{i}}+\frac{0.25}{\zeta-(0.5+0.5 \mathrm{i})}
$$

where $z=X+\mathrm{i} Y$, which is the hump used in the Morland and Boulton (1975) illustrations. Their theory and computer programme were developed for a class of rational mappings determining stress fields under conditions of zero body force and plane strain when the surface is 
subjected to normal and tangential tractions $t_{\mathrm{n}}, t_{\mathrm{s}}$ vanishing at infinity. If $\alpha$ is the local inclination of the surface tangent to $\mathrm{O} x$, then

$$
\mathbf{n}=(-\sin \alpha, \cos \alpha), \quad \mathbf{s}=(\cos \alpha, \sin \alpha) .
$$

A gravity force per unit mass $g \mathbf{k}$ is now included, where

$$
\mathbf{k}=(\sin \delta,-\cos \delta) .
$$

Introduce a stress unit $C$ to normalize the applied pressure fluctuation due to the glacier flow, and let $p_{0}$ be the overburden pressure on the bed line $\mathrm{O} x$, outside the hump, under depth $h$ of ice. Then

$$
p_{0}=\rho g h \cos \delta=C P_{0}
$$

where $\rho$ is the ice density. If the stress $\sigma$ is expressed in the form

$$
\boldsymbol{\sigma}=C\left(\boldsymbol{\Sigma}-P_{0} \mathbf{r}\right)
$$

so $\boldsymbol{\Sigma}$ defines a dimensionless over-stress above an isotropic pressure $P_{0}$, and assuming that there is an isotropic pressure $p_{0}$ near the bed surface outside the influence of the hump loading, $\boldsymbol{\Sigma}$ vanishes at the surface as $X \rightarrow \pm \infty$. Further, let

$$
\boldsymbol{\Sigma}=\mathbf{\Sigma}^{\circ}-R(\mathbf{X} . \mathbf{k}) \mathbf{k} \times \mathbf{k}, \quad R=\frac{\rho_{\mathrm{r}} g a}{C}
$$

where $\rho_{\mathrm{r}}$ is the bedrock density, then $\boldsymbol{\Sigma}^{\circ}$ is a self-equilibrating stress field (zero body-force) to which the Morland and Boulton (1975) theory applies. Note that $Y$, and hence ( $\mathbf{X}$. $\mathbf{k}$ ), vanishes as $X \rightarrow \pm \infty$. If $\mathcal{N}, T$ are the normal and tangential tractions associated with $\mathbf{\Sigma}^{\circ}$, then

$$
\begin{aligned}
& \mathcal{N}=\frac{t_{\mathrm{n}}}{C}+P_{0}+R(\mathbf{X} \cdot \mathbf{k}) \cos ^{2}(\alpha-\delta) \\
& T=\frac{t_{\mathrm{s}}}{C}+\frac{1}{2} \mathbf{R}(\mathbf{X} \cdot \mathbf{k}) \sin (2(\alpha-\delta))
\end{aligned}
$$

The case of $\delta=0$ (horizontal bed line) was used in an analysis of the formation of glacial flutes by Morris and Morland (1976).

Following Morland and Boulton (1975) a model pressure fluctuation based on Nye's (1969) theory, but ignoring the restriction to small slopes, is adopted, together with a crude cavitation approximation $t_{\mathrm{n}}=\mathrm{o}$ whenever the predicted normal traction becomes tensile. Thus

$$
\frac{t_{\mathrm{n}}}{C}+P_{\mathrm{o}}= \begin{cases}-Q(X), & Q+P_{0} \geqslant 0 \\ P_{0}, & Q+P_{0} \leqslant 0\end{cases}
$$

where for the hump surface given by Equation (2) the pressure fluctuation is approximately

$$
Q(X)=0.29 \cos \left[\frac{\pi(x-0.3)}{2.4}\right]-0.96 \sin \left[\frac{\pi(x-0.3)}{2.4}\right]
$$

on $-1.87 \leqslant X \leqslant 2.93$, zero outside the range, and has amplitude unity.

$$
C \approx \mathrm{I} 0 \eta U / \lambda \text { for } \lambda>\mathrm{Im}
$$

where $\eta$ is the ice viscosity, $U$ is the basal sliding velocity and $\lambda$ is the wavelength of the hump, approximately $4.8 a$. Nye (1969) takes $\eta=3 \times 10^{12} \mathrm{~N} \mathrm{~s} \mathrm{~m}^{-2}, U=3 \times 10^{-7} \mathrm{~m} \mathrm{~s}^{-1}$, giving

$$
C \approx\left(10^{6} \rightarrow 10^{7}\right) \mathrm{N} \mathrm{m}^{-2} \quad \text { as } \lambda \approx(10 \rightarrow \mathrm{I}) \mathrm{m} \text {. }
$$

Note that

$$
P_{0} \approx \frac{10^{4} h \cos \delta}{C} \approx\left(10^{-2} \rightarrow 10^{-3}\right)(h / \mathrm{m})
$$


for the stress unit given by Equation ( $\mathrm{I} 3)$ and $\delta \ll \frac{1}{2} \pi$. Thus $P_{\mathrm{o}}<\mathrm{I}$ for $h<\left(\mathrm{IO}^{2} \rightarrow \mathrm{IO}^{3}\right) \mathrm{m}$ and cavitation occurs under these conditions. Also a regelation layer is assumed, to provide perfect slip:

If $\rho_{\mathrm{r}}=3 \rho \approx 3 \times 1 \mathrm{IO}^{3} \mathrm{~kg} \mathrm{~m}^{-3}$,

$$
t_{\mathrm{s}}=\mathrm{o}
$$

$$
R \approx 7 \times \mathrm{IO}^{-4} \lambda^{2} \approx\left(7 \times \mathrm{IO}^{-2} \rightarrow 7 \times \mathrm{IO}^{-4}\right) \quad \text { as } \lambda \approx(\mathrm{IO} \rightarrow \mathrm{I}) \mathrm{m} \text {. }
$$

If $R$ is small, Equations (7) to (9) show that gravity effects are not significant. However, since $R$ is proportional to $\lambda^{2}$ and inversely proportional to $U$ for a given hump profile, Equation ( 16 ) gives $R=O(\mathrm{I})$ if $\lambda=40 \mathrm{~m}, U=3 \times 10^{-7} \mathrm{~m} \mathrm{~s}^{-1}$ or if $\lambda=10 \mathrm{~m}$ and $U=2 \times 10^{-8}$ $\mathrm{m} \mathrm{s}^{-1}$, both practical conditions. Note that the term in $R$ of Equation (8) increases the normal traction $\mathcal{N}$ associated with $\boldsymbol{\Sigma}^{\circ}$ but has the opposite effect in the calculation of the actual overstress $\boldsymbol{\Sigma}$ by Equation (7). The net effect can only be determined by calculated examples. By Equations (12) and (14) $P_{0}$ is proportional to $\lambda$ and inversely proportional to $U$. $P_{0}$ increases under the conditions which lead to an increase in $R$. In fact, since $a \ll h$,

$$
\frac{R}{P_{0}}=\frac{0.6 \lambda}{h \cos \delta}=O(\lambda / h)<\mathrm{I}
$$

for $\delta \ll \frac{1}{2} \pi$. Thus $R=O(\mathrm{I})$ implies $P_{\mathrm{O}}>\mathrm{I}$; that is, the pressure fluctuation is too small for cavitation and Equation (I0) applies everywhere, making $\boldsymbol{\Sigma}^{\circ}$ and $\boldsymbol{\Sigma}$ independent of $P_{0}$ for given $R$.

Consider a Coulomb failure criterion for the bedrock. Failure occurs if

$$
|\tau| \geqslant \tau_{0}-\left(\sigma+p_{\mathrm{w}}\right) \tan \phi
$$

where $\tau_{0}$ is the cohesive stress, $p_{\mathrm{w}}$ the pore-water pressure, $\phi$ the friction angle $\left(0<\phi<\frac{1}{2} \pi\right)$ and $\tau, \sigma$ are the shear and normal tractions on the failure planes which have normals inclined at angles $\pm\left(\frac{1}{4} \pi-\frac{1}{2} \phi\right)$ to the maximum principal stress axis. If $\sigma_{1}, \sigma_{2}$ are the local principal stresses, then $\boldsymbol{\Sigma}$ has the same principal axes with principal values given by

$$
\sigma_{\mathrm{I}}=C\left(\Sigma_{\mathrm{1}}-P_{0}\right), \quad \sigma_{2}=C\left(\Sigma_{2}-P_{0}\right) .
$$

Defining a dimensionless failure stress $S$ by

$$
S=\frac{1}{2}\left|\Sigma_{1}-\Sigma_{2}\right| \sec \phi+\frac{1}{2}\left(\Sigma_{1}+\Sigma_{2}\right) \tan \phi
$$

Equation (18) becomes

$$
S \geqslant \frac{\tau_{0}}{C}+P_{\mathrm{o}}\left(\mathrm{I}-\frac{p_{\mathrm{w}}}{p_{\mathrm{o}}}\right) \tan \phi=S_{\mathrm{c}} .
$$

$S$ is determined everywhere by $\boldsymbol{\Sigma}$ and $\phi$ for a given hump and boundary loading, while $S_{\mathrm{c}}$ depends only on the Coulomb parameters and the stress unit $C$. Failure is initiated whenever $S_{\max }$ exceeds $S_{\mathrm{c}}$. Pore-water pressure $p_{\mathrm{w}}$ can theoretically range from zero to $p_{\mathrm{o}}$ when $S_{\mathrm{c}}$ takes its maximum and minimum values respectively.

$$
\left.\begin{array}{ll}
S_{\mathrm{c}}=P_{\mathrm{o}}\left(\frac{\tau_{\mathrm{o}}}{p_{\mathrm{o}}}+\tan \phi\right), & p_{\mathrm{w}}=0, \\
S_{\mathrm{c}}=P_{\mathrm{o}} \frac{\tau_{\mathrm{o}}}{p_{\mathrm{o}}}, & p_{\mathrm{w}}=p_{0} .
\end{array}\right\}
$$

However, the permeabilities of coherent rocks are very small (Morris and Johnson, 1967). The highest values for intact rock are $\approx 5 \times 10^{-6} \mathrm{~m} \mathrm{~s}^{-1}$ (medium-grained sandstone), $\approx \mathrm{IO}^{-5} \mathrm{~m} \mathrm{~s}^{-1}$ (oolitic limestone) and $\approx \mathrm{IO}^{-6} \mathrm{~m} \mathrm{~s}^{-1}$ (volcanic tuffs). Thus it is unlikely that $S_{\mathrm{c}}$ will be reduced to its minimum value by pore water within the voids of the coherent rock. 
Of course, well-jointed rock has a secondary and much higher permeability arising from the presence of open and continuous cracks and in this case "cleft water pressure" can reduce the strength of the rock significantly (Terzaghi, I962).

By construction $\boldsymbol{\Sigma}$ and $S_{\max }$ are of order unity, so failure can occur only if $S_{\mathrm{c}}$ is of order unity or less. Typical cohesive stresses are $\tau_{0}=5 \times 10^{5} \mathrm{~N} \mathrm{~m}^{-2}$ (siltstone), $(2 \rightarrow 5) \times 10^{6}$ $\mathrm{N} \mathrm{m}^{-2}$ (sandstone) and $10^{7} \mathrm{~N} \mathrm{~m}^{-2}$ (granite). For $h=100 \mathrm{~m}$ the respective values of $\tau_{0} / p_{0}$ are

$$
\frac{\tau_{0}}{p_{0}}=0.5,2 \rightarrow 5, \text { 10, } \quad h=100 \mathrm{~m} .
$$

Thus, even in the case $p_{\mathrm{w}}=p_{0}$, failure is possible only when $P_{0} \leqslant O(2)$ for siltstone, and much smaller for the other rocks, unless $h \gg 100 \mathrm{~m}$. The corresponding friction angles are $\phi=30^{\circ}$, $35^{\circ}$ and $45^{\circ}$, so for $p_{\mathrm{w}}=0$ the required factors are respectively

$$
\frac{\tau_{0}}{p_{0}}+\tan \phi=1.08,2.7 \rightarrow 5.7,1 \mathrm{I}, \quad h=100 \mathrm{~m} .
$$

We have used Nye's theory for the sliding of ice over obstacles with small surface slopes to define $P_{0}$, the ratio of the overburden pressure to the amplitude of the pressure variation across the hump, in terms of $U, \eta$ and $\lambda$. However, the restrictions on $P_{0}$ for failure to occur do not depend on the choice of sliding theory. Consideration of the overall equilibrium of the glacier indicates that it is unlikely that the amplitude of the pressure variation across a finite hump will be much greater than the overburden pressure. Thus we expect $P_{0} \approx O(\mathrm{I})$. Nye's theory gives $P_{0}=p_{0} \lambda / 2 \eta U$, which may take smaller values (Equation (14)). Larger $h$ increases $p_{0}$, and larger $U$ decreases $P_{0}$ for given $p_{0}$, both effects decreasing $S_{\mathrm{c}}$.

Since the stress field cannot be influenced significantly by the gravity terms unless $R=O(\mathrm{I})$; which implies $P_{\mathrm{o}}>\mathrm{I}$ and hence $S_{\mathrm{c}}>\mathrm{I}$, gravity will not affect failure conditions.

\section{Illustrations}

The stress fields in the elastic hump defined by Equation (2) have been calculated for various values of $P_{0}$ and $R$ in the case $\delta=0$. In Figure 2 the variation of $S_{\max }$ with $P_{0}$ for $\phi=30^{\circ}$ and $R=0,0.5, \mathrm{I}$ and the variation of $S_{\mathrm{c}}$ with $P_{0}$ for $\phi=30^{\circ}, p_{\mathrm{w}}=0$ and $\tau_{\mathrm{o}} / p_{0}=0$, 0.5 are compared. Failure will occur if $S_{\max } \geqslant S_{\mathrm{c}}$. A siltstone hump under $100 \mathrm{~m}$ of ice $\left(\tau_{0} / p_{0}=0.5\right)$ will fail if $P_{0} \leqslant 0.3(R=0), P_{0} \leqslant 0.45(R=0.5)$ or $P_{0} \leqslant 0.65(R=\mathrm{I})$. The $R=\mathrm{I}$ curve is however not physically relevant for $P_{0} \leqslant \mathrm{I}$. As $h$ increases $\tau_{0} / p_{0} \rightarrow 0$ and failure can occur at higher values of $P_{0}$. The analogous curves for sandstone and granite are shown in Figures 3 and 4 respectively. In these cases also failure will only occur for low values of $P_{0}$ when $h=100 \mathrm{~m}$. Since from Nye's theory $P_{0}$ is inversely proportional to $U$ and proportional to $\lambda$, for a given value of $p_{0}$, failure is most likely for high basal sliding velocity and a small hump.

Figures 2 to 4 show that $S_{\max }$ increases with $P_{0}$ to a level $S_{0}$ at $P_{0}=1$ and then remains constant at $S_{0}$. Below $P_{0}=\mathrm{I}$ the curve for $R=\mathrm{o}$ is not quite linear because the point of maximum stress moves from inside the hump to the surface of the down-stream flank. For $R \gtrsim 0.2$ the point of maximum stress is on the down-stream surface for all $P_{0}$.

The failure criterion (18) holds if $P_{0} \leqslant \mathrm{I}$ and

$$
S_{0} \geqslant \tan \phi+\frac{\tau_{0}}{p_{0}} \text {. }
$$

That is, failure occurs if the cohesive stress satisfies

$$
\tau_{0} \leqslant \tau_{\mathrm{f}}=\operatorname{I0} \eta\left(S_{0}-\tan \phi\right) U / \lambda
$$

when $P_{0} \leqslant \mathrm{I}$. For $P_{0} \geqslant \mathrm{I}$ smaller $\tau_{0}$ is required. Figure 5 shows the variation of $\tau_{\mathbf{f}}$ with $\lambda$ for $\phi=30^{\circ}, p_{\mathrm{w}}=\mathrm{o}$ and $R=\mathrm{o}$ (appropriate to low values of $P_{0}$ ). Failure will occur if 


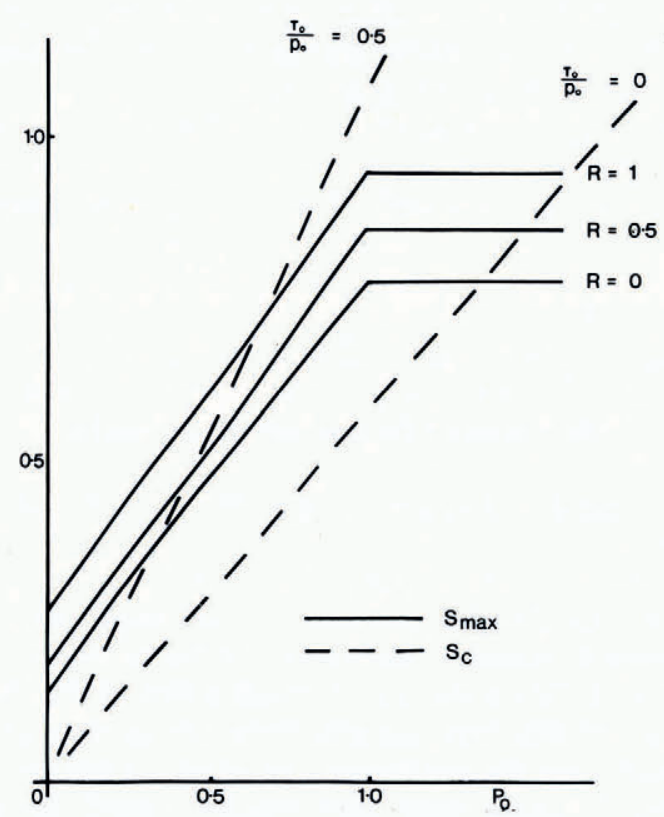

Fig. 2. $S_{\max }$ and $S_{\mathrm{c}}$ as functions of $P_{0}$ for $\phi=30^{\circ}$ and $p_{\mathrm{w}}=o$. For a siltstone hump under $100 \mathrm{~m}$ of ice $\left(\tau_{\mathrm{o}} / p_{0}=0.5\right)$ $S_{\max } \geqslant S_{\mathrm{c}}$ and failure will occur when $P_{\mathrm{o}} \leqslant 0.3(R=0), P_{0} \leqslant 0.45(R=0.5)$ or $P_{0} \leqslant 0.65(R=I)$.

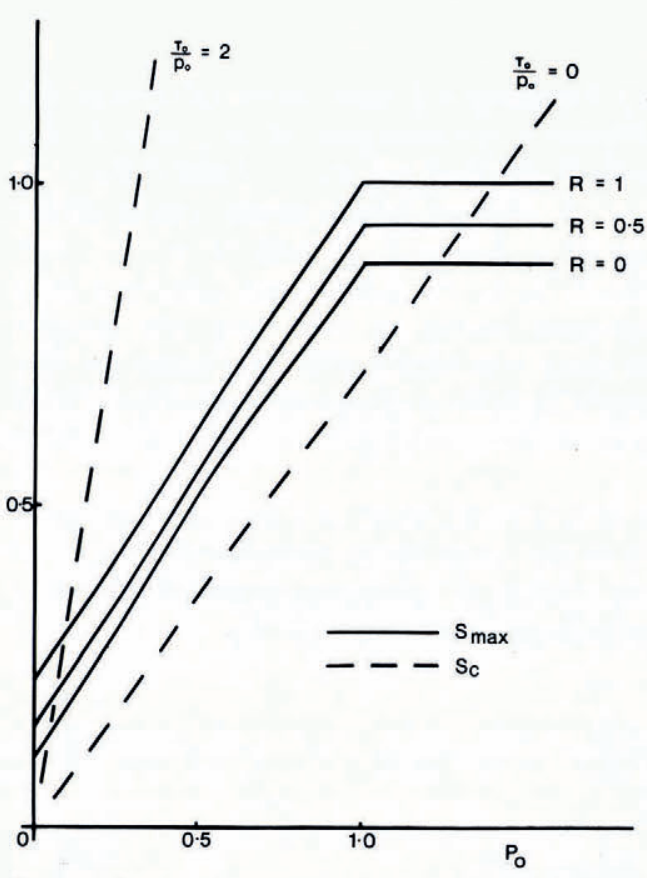

Fig. 3. $S_{\max }$ and $S_{\mathrm{c}}$ as functions of $P_{0}$ for $\phi=35$ and $p_{\mathrm{w}}=0$. For a sandstone hump under $100 \mathrm{~m}$ of ice $\left(\tau_{0} / p_{0} \approx 2\right) S_{\max } \geqslant S_{\mathrm{c}}$ and failure will occur when $P_{0} \leqslant 0.04(R=0), P_{0} \leqslant 0.06(R=0.5)$ or $P_{0} \leqslant 0.09(R=I)$.

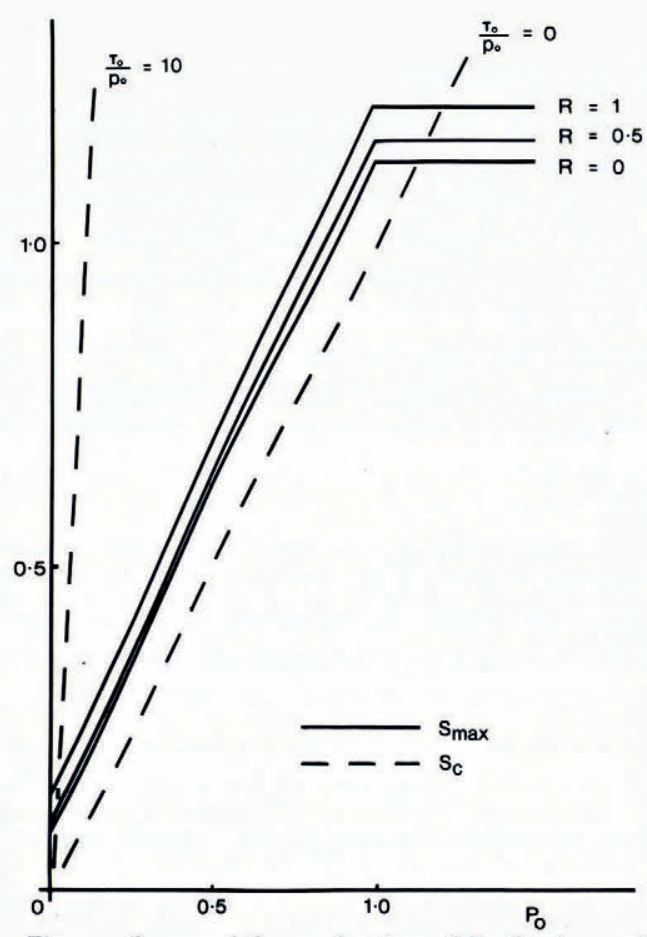

Fig. 4. $S_{\max }$ and $S_{\mathrm{c}}$ as functions of $P_{\mathrm{o}}$ for $\phi=45$ and $p_{\mathrm{w}}=0$. For a granite hump under $100 \mathrm{~m}$ of ice $\left(\tau_{\mathrm{o}} / p_{0} \approx 10\right) S_{\max } \geqslant S_{\mathrm{c}}$ and failure will occur when $P_{0} \leqslant 0.01$ for $R \leqslant I$. 
$\tau_{\mathrm{f}} \geqslant \tau_{0}$. Siltstone humps with $\tau_{0} \approx 5 \times 10^{5} \mathrm{~N} \mathrm{~m}^{-2}$ will fail if $\lambda \leqslant 3 \mathrm{~m}\left(U=3 \times 10^{-7} \mathrm{~m} \mathrm{~s}^{-1}\right)$, $\lambda \leqslant 12 \mathrm{~m}\left(U=10^{-6} \mathrm{~m} \mathrm{~s}^{-1}\right)$ or $\lambda \leqslant 37 \mathrm{~m}\left(U=3 \times 10^{-6} \mathrm{~m} \mathrm{~s}^{-1}\right)$. A basal sliding velocity of $U=3 \times \mathrm{IO}^{-6} \mathrm{~m} \mathrm{~s}^{-1}$ is unusually fast for a normal (non-surging) temperate glacier to which the Nye theory is expected to apply. Analogous curves are shown for $\phi=35^{\circ}$ in Figure 6 . Sandstone humps, with a minimum $\tau_{0}$ of $2 \times 10^{6} \mathrm{~N} \mathrm{~m}^{-2}$, will fail if $\lambda \leqslant 3 \mathrm{~m}\left(U=10^{-6} \mathrm{~m} \mathrm{~s}^{-1}\right)$ or $\lambda \leqslant$ ro m $\left(U=3 \times 10^{-6} \mathrm{~m} \mathrm{~s}^{-1}\right)$.

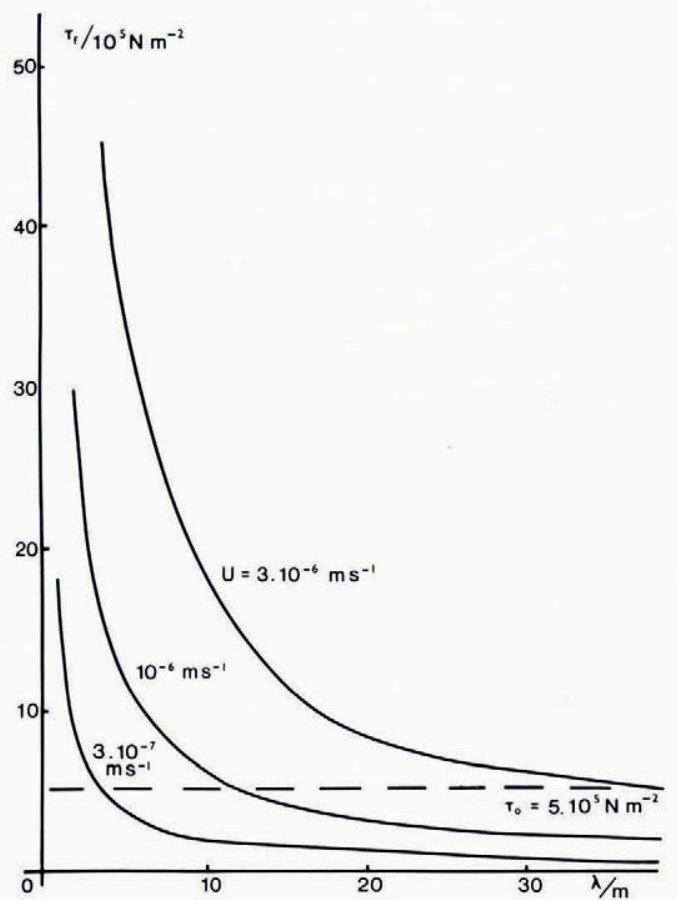

Fig. 5. $\tau_{\mathrm{f}}$ as a function of $\lambda$ for $\phi=30^{\circ}, p_{\mathrm{W}}=o$ and $R=o$. Failure occurs when $\tau_{\mathrm{f}} \geqslant \tau_{0}$. Siltstone humps will fail if $\lambda \leqslant 3 \mathrm{~m},\left(U=3 \times 10^{-7} \mathrm{~m} \mathrm{~s}^{-1}\right)$, $\lambda \leqslant 12 \mathrm{~m}\left(U=10^{-6} \mathrm{~m} \mathrm{~s}^{-1}\right)$ or $\lambda \leqslant 37 \mathrm{~m}$ $\left(U=3 \times 10^{-6} \mathrm{~m} \mathrm{~s}^{-1}\right)$.

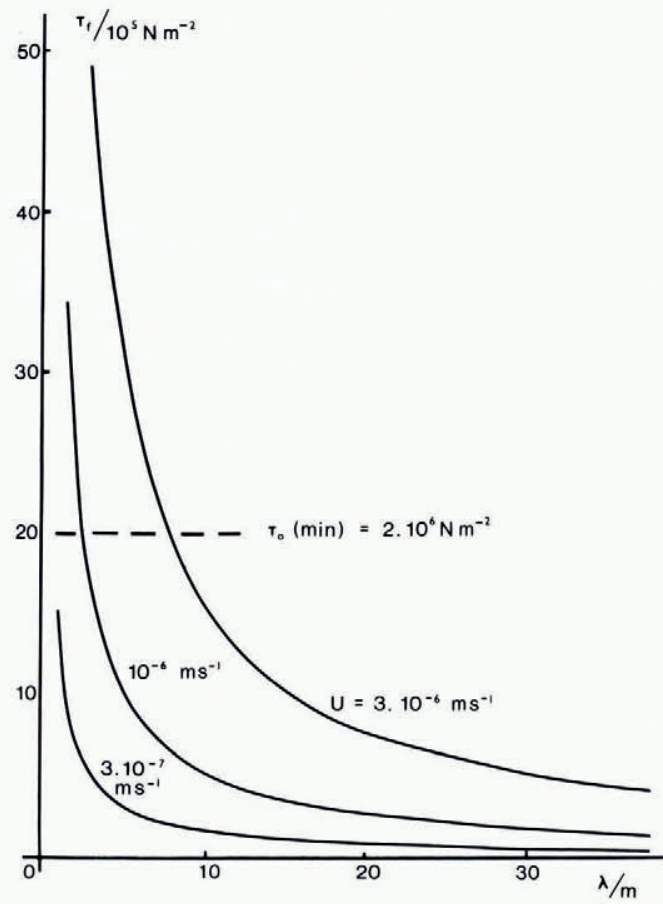

Fig. 6. $\tau_{\mathrm{f}}$ as a function of $\lambda$ for $\phi=35^{\circ}, p_{\mathrm{w}}=o$ and $R=o$. Failure occurs when $\tau_{\mathrm{f}} \geqslant \tau_{0}$. Sandstone humps will fail if $\lambda \leqslant 3 \mathrm{~m}\left(U=10^{-6} \mathrm{~m} \mathrm{~s}^{-1}\right)$ or $\lambda \leqslant \operatorname{rom}\left(U=3 \times 10^{-6} \mathrm{~m} \mathrm{~s}^{-1}\right)$.

The region of the hump where failure is most likely to occur is shown for various values of $P_{0}$ and $R$ in Figures 7 to io. Figure 7 shows the variation of $S$ for $\phi=35^{\circ}, R=0$ and $P_{0}=0.5$. The maximum value, $S_{\max }=0.5 \mathrm{I}$, is not adjacent to the point of closure of the cavity as the previous analysis of this case (Morland and Boulton, 1975) suggested, but deep within the down-stream flank of the hump. If $R$ is increased to 0.5 , about the largest physically reasonable value if $P_{0}=0.5$, the maximum value of $S$ increases slightly to 0.547 (Fig. 8) and is found on the down-stream surface just below the steepest portion but well up-stream of the point of closure of the cavity. Failure and subsequent removal of material in this region would tend to steepen the down-stream flank. Figure 9 shows the variation of $S$ for $\phi=35^{\circ}$, $R=\mathrm{o}$ and $P_{0}=\mathrm{I}$. The maximum value of $S$ is 0.872 and occurs on the surface just downstream of the point where the ice exerts minimum pressure on the rock. Increasing the value of $R$ to I (Fig. Io) leads to an increase in the magnitude of $S_{\max }$ to I.or6. Its position does not change. Again any failure would tend to steepen the down-stream flank. 


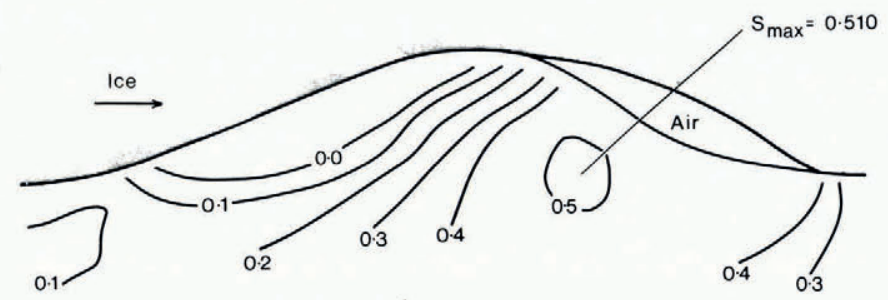

Fig. 7 . The inriation of $S$ for $\phi \quad 3 ., R$ o and $P_{0} \quad$ 1).;.

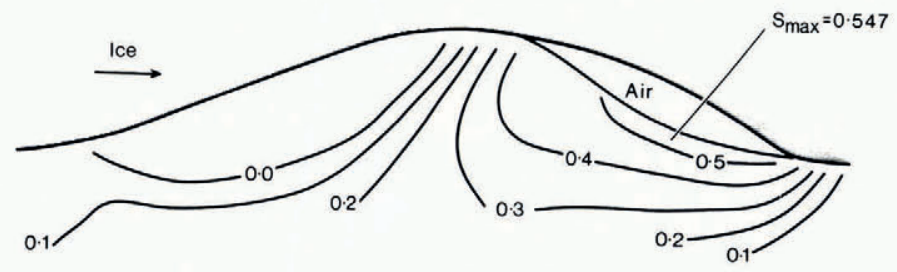

Fig. 8. The iariation of $S$ for $\phi \quad 3.5, R-10.5$ and $P_{0}=0.5$.

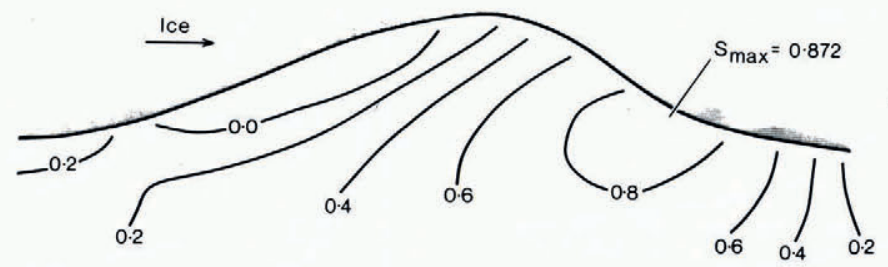

Fig. 9. The variation of $S$ for $\phi \cdots 35, R=0$ and $P_{\mathrm{n}} \quad t$.

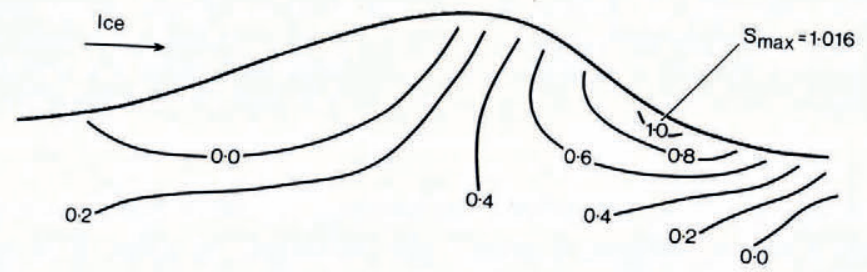

Fig. 10. The variation of $S$ for $\phi=35^{\circ}, R=I$ and $P_{0}=I$.

\section{Conclusion}

We have shown that in general the force exerted by a glacier on an obstacle of a given roche-moutonnée-like shape will not be sufficient to produce Coulomb failure if the rock is coherent. This profile and all other less skew profiles are stable unless jointing introduces an easier failure mechanism. Thus we follow Lewis (1954) in suggesting that the typical "rochemoutonnée" profile of obstacles on a glacier bed, from large stream-lined boulders to valley steps, cannot develop unless the rock is already jointed. 


\section{Acknowledgement}

This investigation was pursued in connection with Natural Environment Research Council grant $\mathrm{GR}_{3} / 2680$ "Flow of glaciers over deformable materials" held jointly with Dr G. S. Boulton in the School of Environmental Sciences.

MS. received I2 April 1976

\section{REFERENCES}

Lewis, W. V. 1954. Pressure release and glacier erosion. Fournal of Glaciology, Vol. 2, No. 16, p. 416-22.

Morland, L. W., and Boulton, G. S. 1975. Stress in an elastic hump: the effects of glacier flow over elastic bedrock. Proceedings of the Royal Society of London, Ser. A, Vol. 344, No. I637, p. I 57-73.

Morris, D. A., and Johnson, A. I. 1967. Summary of hydrologic and physical properties of rock and soil materials, as analyzed by the Hydrologic Laboratory of the U.S. Geological Survey 1948-6o. U.S. Geological Survey. Water-Supply Paper 1839-D.

Morris, E. M., and Morland, L. W. 1976. A theoretical analysis of the formation of glacial flutes. Fournal of Glaciology, Vol. I 7, No. 76, p. 31 i-23.

Nye, J. F. 1969 . A calculation on the sliding of ice over a wavy surface using a Newtonian viscous approximation. Proceedings of the Royal Society of London, Ser. A, Vol. 31 I, No. 1506, p. 445-67.

Terzaghi, K. 1962. Stability of steep slopes on hard unweathered rock. Géotechnique (London), Vol. 12, No. 4, p. $25 \mathrm{I}-63,269-70$. 